\title{
A Theory of Blossom Thinning to Consider Maximum Annual Flower Bud Numbers on Biennial Apple Trees
}

\author{
Brian P. Pellerin ${ }^{1}$ \\ Department of Plant and Animal Sciences, Nova Scotia Agricultural College, \\ PO Box 550, Truro, NS B2N 5E3 Canada
}

\author{
Deborah Buszard \\ College of Sustainability, Dalhousie University, 6050 University Avenue, \\ Halifax, NS B3H 1 W5 Canada
}

\author{
David Iron \\ Department of Mathematics and Statistics, Dalhousie University, Halifax, NS \\ B3H $3 J 5$ Canada
}

Charles G. Embree

Atlantic Food and Horticultural Research Centre, Agriculture and Agri-Food Canada, 32 Main Street, Kentville, NS B4N IJ5 Canada

Richard P. Marini

Department of Horticulture, Pennsylvania State University, 102 Tyson Building, University Park, PA 16802

\section{Douglas S. Nichols \\ Nova Scotia Fruit Growers' Association, Agriculture and Agri-Food Canada, 32 Main Street, Kentville, NS B4N IJ5 Canada \\ Gerald H. Neilsen and Denise Neilsen \\ Agriculture and Agri-Food Canada, Pacific Agri-Food Research Centre, 4200 Highway 97, Summerland, BC VOH 1 Z0 Canada}

Additional index words. maximum annual flower bud number, early flower thinning, mathematical modeling, optimization

\begin{abstract}
Tree fruit growers use chemical and mechanical thinning techniques in an attempt to maintain regular annual flower production and maximum repeatable yields of varieties susceptible to biennial bearing. If the percentage of floral buds an apple tree could produce without causing yield depression in subsequent years was known, it would be possible to better manage crop-thinning regimes. This study proposes that thinning is a partial transfer of potential flower buds from one year to the next year and estimates the maximum repeatable sequence of flower buds without biennial bearing. The conceptual framework is tested on a 50 -year simulation with $0 \%$ to $100 \%$ transfer of thinned flower buds. Results indicate that the maximum repeatable sequence of flower buds rises sharply when the final years of the orchard approach and declines when the percent transfer of thinned buds is near $0 \%$.
\end{abstract}

Regular yields of good-quality fruits are essential for modern apple growers; however, many cultivars such as Honeycrisp suffer alternate bearing and, more precisely, biennial

Received for publication 27 Sept. 2010. Accepted for publication 12 Nov. 2010.

Funding was provided by the MITACS Accelerate program.

We acknowledge Dalhousie University, Atlantic Food and Horticulture Research Centre, the Nova Scotia Fruit Growers' Association, and the Nova Scotia Agricultural College for supporting this project.

${ }^{1}$ To whom reprint requests should be addressed; e-mail pellerinb@nsac.ca. diseases can all induce biennial bearing in apple trees (Landsberg and Thorpe, 1975; Singh, 1948; Wilkie et al., 2008). In years of heavy bloom, fruit growers may remove excess flowers and fruitlets chemically or by hand to increase fruit size of the current crop and encourage return bloom (Davies, 1950; Wertheim, 2000). To increase flower bud initiation, timing of flower removal is critical; it is most effective to remove whole flower buds, including leaves, during winter dormancy [termed bud or spur extinction by Lauri et al. (1995)] and least effective to remove only the flowers or fruitlets during or after flowering because anthesis and seed development both significantly impact return bloom (Dennis, 2000; Nichols et al., in press; Singh, 1948).

Removing flowers in one year can be viewed as partially transferring potential flowers and fruit to the subsequent year; this has been demonstrated in numerous studies on thinning biennially bearing apple cultivars described in the review by Dennis (2000). Hypothetically there must be an optimal thinning regime that would provide good fruit size and consistent return bloom and yield every year, leading to predictable annual harvest and maintenance of healthy trees.

Observation of data from the 10-year NC140 'Royal Gala' rootstock trial in Geneva, NY (Barritt et al., 1997) and the six-year fertigation trial in Summerland, British Columbia, Canada (Neilsen et al., 2009) provided the conceptual framework behind this study. The data show distinct year-to-year fluctuations in yield. Potentially higher yields in one year might be considered to be "transferred" to a year of subsequently lower yield by thinning. The purpose of this article is to model the effects of thinning on yearly flower bud number and determine the maximum annual number of flower buds on an apple tree for the life of the orchard. The maximum annual number of flower buds is defined as the largest number of flower buds an apple tree could produce in any year and maintain or increase numbers in every year thereafter.

\section{Theory and Model}

Biennial apple trees produce alternate numbers of few or many flower buds each year. To regulate the number of flower buds, fruit growers remove (thin) some when they are too numerous. For this model, the percentage of floral buds is assumed to be a random value between $0 \%$ and $50 \%$ and in alternate years between $50 \%$ and $100 \%$. The percentage of floral buds is defined as the number of floral buds relative to the total number of buds on a tree (Lombard and Richardson, 1982). This assumes that the biennial tendency of a mature apple tree is constant.

Suppose the number of flower buds (FBs) is recorded for three consecutive years as $F B_{1}, F B_{2}, F B_{3}$.

Thinning done in any year $i$ removes $\alpha_{i}$ flower buds from $F B_{i}$ leaving $\overline{F B_{i}}=F B_{i}-\alpha_{i}$. Suppose for $\alpha_{i}$ flower buds removed, $\alpha_{i} b$ are added to the next year where $b$ is the percentage of floral buds removed in one year 
and transferred to the next as a result of thinning. The parameter $b$ is a measure of thinning effectiveness. The value $b=1.0$ represents $100 \%$ transfer of floral buds removed in one year to the next as a result of thinning before anthesis. The value $b=0.0$ represents $0 \%$ transfer of floral buds removed in 1 year to the next as a result of thinning after fruit set, which is ineffective at improving return bloom (Dennis and Neilsen, 1999; Singh, 1948). Thinning in the first year increases the number of flower buds in the next year, which would decrease the number of flower buds in the year after and affect every upcoming year in the following way. $F B_{1}-\alpha_{1}, F B_{2}+\alpha_{1} b, F B_{3}-$ $\alpha_{1} b$. This model fixes the value of $b$ to be the same for all years to show how different thinning regimes influence the maximum annual flower bud number.

To prevent biennial bearing, there should be no decrease in flower bud numbers from year to year. This restricts the maximum annual percentage of flower buds for the first year to be $\overline{F B_{1}}=\operatorname{MIN}\left\{F B_{1},\left(F B_{2}+F B_{1} * b\right) /\right.$ $\left.(1+b),\left(F B_{3}+F B_{2} * b\right) /(1+b)\right\}$ and the general equation to be

$$
\begin{aligned}
\overline{F B_{i}}= & M I N\left\{F B_{i}+\alpha_{i-1} * b,\right. \\
& \left(F B_{i+1}+F B_{i} * b\right) /(1+b), \ldots, \\
& \left.\left(F B_{n}+F B_{n-1} * b\right) /(1+b)\right\}
\end{aligned}
$$

ensuring that $\overline{F B_{1}} \leq \overline{F B_{2}} \leq \ldots \leq \overline{F B_{n}}$ and maximizing the values beginning from $\overline{F B_{1}}$ to $\overline{F B_{n}}$. A simulation of 50 seasons was run as a macro in Excel 2007 (Microsoft Inc., Redmond, WA) with parameter $b$ run from 0 to 1 at intervals of 0.01 and replicated 10,000 times with half the seasons beginning with a random value between 0 and 0.5 and half beginning with a random value between 0.5 and 1.

\section{Results}

Values for maximum annual percent of flower buds from Years 2 to 50 were plotted using SigmaPlot 11.0 (Systat Software Inc., San Jose, CA) (Fig. 1). The first value is unique to the number of years and considered an artifact of the model; therefore, this value is ignored in the results.

Figure 1 shows the simulation running for 50 years, clearly beyond the normal cropping life of an apple tree. The model suggests that the percentage of floral buds that should remain on a tree is dependent on the number of years into the future the tree is expected to be producing fruit. Running the model over shorter periods produces the same result; for example, if a 30-year production period were simulated, it would look like Years 21 to 50 shown in Figure 1. The percentage of floral buds does not form a straight line from the first to final years of production. The strong increase predicted by the model in the percentage of floral buds that can be kept on the tree as the final years of the orchard approach results from the decreasing mathematical probability of a year of poor return bloom as the number of years remaining in the model calculation diminishes. This is not what is observed in reality but is because Eq. [1] uses data from future years to calculate the maximum repeatable flower number for any one year.

The parameter $b$ is a measure of thinning effectiveness. The value $b=1.0$ represents $100 \%$ transfer of floral buds removed in one year to the next as a result of thinning before anthesis. The value $b=0.0$ represents $0 \%$ transfer of floral buds removed in one year to the next as a result of thinning after fruit set, which is ineffective at improving return bloom (Dennis and Neilsen, 1999; Singh, 1948).

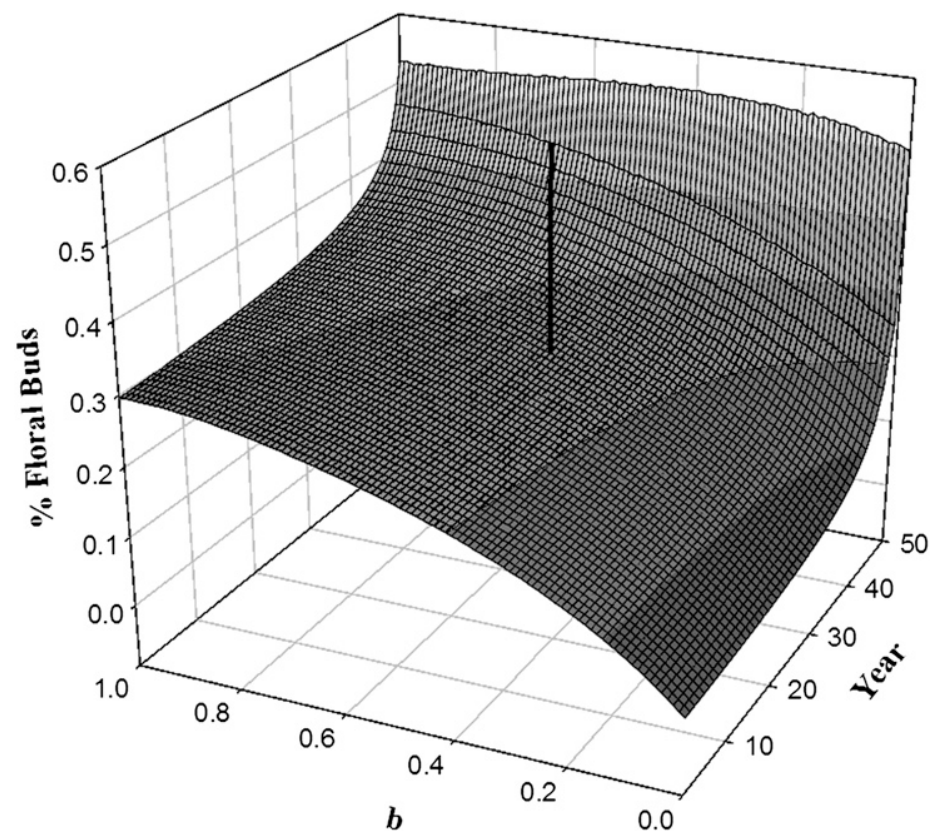

Fig. 1. Graph of the model results based on a 50-year simulation replicated 10,000 times. Parameter $b$ is the percentage of floral buds removed in one year and transferred to the next as a result of thinning. The vertical line intersecting the graph indicates the location of Year 30 and $b=0.5$ where the maximum repeatable percent floral buds is $26 \%$.
The maximum annual percentage of floral buds is sensitive to values of $b$ near $b=0$ as indicated by the steepening slope from $b=1$ to $b=0$ (Fig. 1). According to the model, if thinning were done when $b=0.5$ on trees intended to produce fruit for another 20 years, flower bud thinning should leave $26 \%$ bloom on the tree as indicated at the intersection of the vertical line with the graph in Figure 1.

\section{Discussion}

The theory may be useful for apple growers because it offers a conceptual framework on which to base a blossom management program to regulate cropping throughout the life of the tree. Simply stated, the flower bud number next year should always be at least the flower bud number this year. Ensuring that flower bud numbers are maintained allows for regular annual cropping.

The equation presented in this article can determine a maximum repeatable number of flower buds from real or simulated flower bud data and may be useful in managing biennial apple cultivars such as Honeycrisp. It may be possible to develop a management strategy to control biennial bearing based on this model.

Early flower bud thinning of high-value cultivars is becoming more practical with new mechanical methods (Embree and Nichols, 2005; Roche and Masseron, 2002; Schupp et al., 2008). This model may offer a way to better manage biennial bearing; it may act as a catalyst for development of more real and useful tools to manage flower bud numbers and regulate cropping from year to year. Data are needed to refine the model and investigate major environmental and endogenous factors that affect bienniality. The model will be improved by iteration with more data sets and field testing in various management systems and growing conditions. We welcome input from other researchers and look forward to collaborating and refining this tool. As this work continues, growers may be able to access information like this for any cultivar and rootstock combination.

\section{Literature Cited}

Barritt, B.H., J.A. Barden, J. Cline, R.C. Granger, M.M. Kushad, R.P. Marini, M. Parker, R.L. Perry, T.L. Robinson, C.R. Unrath, and M.A. Dilley. 1997. Performance of Gala at year 5 with eight apple rootstocks in an 8-location NC-140 trial. Acta Hort. 451:129-135.

Davies, M.H.E. 1950. Towards the control of biennial bearing. Ann. Rep. East Malling Res. Stn. 33:154-155.

Davis, D.E. 2002. Inhibition of flower bud initiation and development in apple by defoliation, gibberellic acid and crop load manipulation. $\mathrm{PhD}$ thesis, Virginia Polytechnic Institute, Blacksburg, VA.

Dennis, F.G., Jr. 2000. The history of fruit thinning Plant Growth Regulat. 31:1-16.

Dennis, F.G., Jr. 2003. Flowering, pollination and fruit set development. In: Ferree, D.C. and I. Warrington (eds.). Apples: Botany, production and uses. CABI Publ., Wallingford, UK.

Dennis, F.G., Jr. and J.C. Neilsen. 1999. Physiological factors affecting biennial bearing in tree 
fruit: The role of seeds in apple. HortTechnology 9:317-322.

Embree, C.G. and D.S. Nichols. 2005. Bio-regulators improve fruit size and colour and reduce crop-load and annual bearing of Honeycrisp ${ }^{\mathrm{T} M}$ apples. Can. J. Plant Sci. 85:453-455.

Landsberg, J.J. and M.R. Thorpe. 1975. The mechanisms of apple bud morphogenesis: Analysis and a model. Ann. Bot. (Lond.) 39:689699.

Lauri, P.-E., E. Térouanne, J.-M. Lespinasse, J.-L. Regnard, and J.-J. Kelner. 1995. Genotypic differences in the axillary bud growth and fruiting pattern of apple fruiting branches over several years-An approach to regulation of fruit bearing. Sci. Hort. 64:265-281.

Lombard, P.B. and D.G. Richardson. 1982. Increase fruit set and cropping of 'Comice' pear trees with an ethylene inhibitor, amino-ethoxyvinylglycine. Acta Hort. 124:165-170.

Neilsen, G.H., D. Neilsen, and L. Herbert. 2009. Nitrogen fertigation concentration and timing of application affect nitrogen nutrition, yield, firmness, and color of apples grown at high density. HortScience 44:1425-1431.

Nichols, D., C.G. Embree, and S.A.E. Fillmore. Dormant spur-wood pruning severity impact on vegetative growth, blossom intensity and fruit weight of 'Honeycrisp' apple trees. 9th International Orchard Systems Symposium, August 2008, Geneva, NY. Acta Hort. In press.

Pavičić, N., T. Jemrić, M. Skendrović, and T. Ćosić. 2004. Tree canopy pruning does not regulate biennial bearing in 'Elster' apple (Malus domestica Borkh.). Agriculture Scientific and Professional Review. 10:32-35.
Roche, L. and A. Masseron. 2002. Éclaircissage mécanique des boutons floraux: Darwin et le Mur fruitier. Infos-Ctifl 185:29-33.

Schupp, J.R., T. Auxt Baugher, S.S. Miller, R.M. Harsh, and K.M. Lesser. 2008. Mechanical thinning of peach and apple trees reduces labour input and increases fruit size. HortTechnology 18:660-670

Singh, L.B. 1948. Studies in biennial bearing. IV. Bud-rubbing, blossom thinning and defoliation as possible control measures. J. Hort. Sci. 24: 159-177.

Wertheim, S.J. 2000. Developments in the chemical thinning of apple and pear. Plant Growth Regulat. 31:85-100.

Wilkie, J.D., M. Sedgley, and T. Olesen. 2008. Regulation of floral initiation in horticultural trees. J. Exp. Biol. 59:3215-3228. 